\title{
OPINIÃO PÚBLICA, MÍDIA E MOVIMENTOS SOCIAIS: OS JOVENS E O MST EM TEMPOS DE SOCIEDADE EM REDE
}

\author{
ANELISE LORENZON MACHADO \\ Universidade Federal de Santa Maria \\ Frederico Westphalen, Rio Grande do Sul, Brasil \\ E-mail:machado_anelise@hotmail.com. \\ PATRÍCIA MILANO PÉRSIGO \\ Universidade Federal de Santa Maria \\ Frederico Westphalen, Rio Grande do Sul, Brasil \\ E-mail: patricia.persigo@ufsm.br.
}


OPINIÃO PÚBLICA, MÍDIA E MOVIMENTOS SOCIAIS: OS JOVENS E O MST EM TEMPOS DE SOCIEDADE EM REDE

Resumo: $O$ trabalho trata sobre a formação da opinião dos jovens a respeito dos movimentos sociais, mais especificamente o Movimento dos Trabalhadores Rurais Sem Terra (MST). Apresentamos a formação da esfera pública, a estruturação dos movimentos sociais e suas formas de inserção na mídia. Realizamos uma pesquisa de opinião pública numa escola de ensino médio na cidade de Ronda Alta/RS.

Palavras-chave: Opinião Pública; Mídia; MST; Sociedade em Rede;

\section{LA OPINIÓN PÚBLICA, LOS MEDIOS DE COMUNICACIÓN Y MOVI- MIENTOS SOCIALES: LOS JÓVENES Y EL MST EN LOS TIEMPOS DE LA SOCIEDAD RED}

Resumen: El trabajo se ocupa de la formación de la opinión de los jóvenes sobre los movimientos sociales, especialmente el Movimiento de los Trabajadores Rurales Sin Tierra (MST). Aquí está la formación de la esfera pública, la estructuración de los movimientos sociales y las formas de integración en los medios de comunicación. Se realizó una encuesta de opinión pública en una escuela secundaria en la ciudad de Ronda Alta / RS.

Palabras clave: Opinión Pública; medios de Comunicación; MST; Sociedad Red;

PUBLIC OPINION, MEDIA AND SOCIAL MOVEMENTS: YOUTHS AND THE MST IN TIMES OF NETWORK SOCIETY

Abstract: The paper deals with the opinion construction of youth related to social movements, more specifically The Movement of Landless Rural Workers (MST). We present the construction of the public sphere, the structure process of social movements and their forms of media insertion. We conducted a public opinion research in a High School in Ronda Alta City/RS. Key-words: public opinion; Media; MST; Network society; 


\section{INTRODUÇÃO}

Ligados ao terceiro setor, os movimentos sociais', baseados na sua ideologia, buscam, cada vez mais, formas de adquirir visibilidade. Junto às estratégias de agendamento midiático, buscam estar visíveis para conquistar mais adeptos e disseminar as suas plataformas de reivindicações, garantindo a permanência dos ideais para alcançar mudanças na esfera social.

Os MS precisam da mídia para conseguir destaque, uma vez que ela detém e garante espaços de visibilidade, trabalho exercido através de suas pautas. Portanto, ao conquistarem presença midiática, os $\mathrm{MS}^{2}$ poderão, conforme Toro e Werneck (1996), convocar mais vontades. No entanto, se o enfoque das notícias for negativo, por exemplo, o efeito será ao contrário e, ao invés da captação de mais adeptos, poderá gerar a repulsa aos ideais dos movimentos.

Atualmente, a utilização das mídias pelos MS é uma das principais fontes de novos participantes. Planejar a melhor forma de conquistar espaços nos meios de comunicação é, hoje, essencial para a sobrevivência dos mesmos. Se as estratégias de inserção nas mídias obtiverem resultados, os MS conseguirão uma forma de influenciar na opinião pública, refletindo as suas plataformas de trabalho. E é esse o ponto que interligamos com a problematização do nosso estudo: uma vez que as mídias possuem influência na determinação de assuntos de discutibilidade 3 no seio social, queremos, então, saber como se dá a formação da opinião pública dos jovens sobre os MS.

Ações de mobilização e engajamento em projetos de mudanças sociais são algumas das marcas importantes nos processos históricos dos MS. A cada nova forma de engajar adeptos, os movimentos ganham mais força e vitalidade na busca pela realização dos seus projetos. Segundo Simeone (2012, p.2), "o termo mobilização social tem-se tornado cada vez mais corrente no Brasil para designar uma prática de movimentação de pessoas e instituições, essencial para o exercício da cidadania num contexto democrático".

Realizamos uma pesquisa de opinião pública para entendermos como se dá a formação da opinião pública sobre os movimentos sociais, principalmente do Movimento dos Trabalhadores Rurais Sem Terra (MST). Que-

1 Em trechos do texto, para síntese da leitura, será utilizada sigla “MS” para referenciar os movimentos sociais.

2 Movimentos Sociais

3 Entendemos “discutibilidade" como o potencial de propiciar uma discussão. 
remos entender como o movimento atinge os moradores da cidade Ronda Alta4, localizada no norte do Rio Grande do Sul, principalmente aqueles que darão continuidade aos ideais, os jovens. Por ser um dos assentamentos com maior produção de alimentos e de contribuição cooperativa entre os seus membros, entendemos que se faz necessário o estudo da formação da opinião de um público estratégico: os jovens.

Lembramos que a mobilização da sociedade está intrinsecamente ligada aos processos de comunicação. Nesse sentido, relacionaremos estudos que abordam a mídia, a opinião pública, os MS, a mobilização e, principalmente, a abertura da democracia - ponto primordial para o engajamento de novos adeptos sem repressão social. Segundo Simeone (2012, p.5) "os processos de mobilização são vistos como requisitos para a prática democrática, que demanda participação ativa dos sujeitos e engajamento cívico".

O MST, ao longo da sua existência, buscou formas de pautar a mídia e de se fazer presente da maneira mais positiva possível. As mudanças em sua estrutura fizeram com que se tornasse um movimento mais organizado, constituído por profissionais de comunicação, os quais atuam na disseminação de informações referentes ao movimento. O MST também adentrou nas mídias sociais digitais, possuindo um alcance maior na divulgação do que acontece em todos os assentamentos e acampamentos do movimento, difundindo as suas visões e o seu papel na sociedade. Dessa forma, as informações do grupo alcançam uma amplitude maior e com mais chances de se tornarem positivas e de perpetuarem-se no tempo, através das gerações, minimizando um possível passado negativo da imagem do movimento na mídia.

Percebemos que a mídia tradicional promove, por vezes, uma visão negativa dos MS, principalmente em relação ao nosso objeto empírico. Por esse motivo, consideramos importante verificar como, em um local onde o MST possui assentamento - e, de uma forma ou outra, auxilia na produção da economia local -, se forma a opinião dos jovens, ultrapassando o conhecimento expresso pelos meios de comunicação de massa.

Para Peruzzo (1998), os MS passam, ao longo do tempo, por mudanças

4 A Fazenda Anonni, situada na região, foi um marco para o MST, pois é o primeiro assentamento conquistado por resistência do movimento. Em julho de 2014, o local completa 27 anos de existência. Já em relação à escolha do município, a cidade de Ronda Alta foi selecionada pelo fato de ter sido a primeira a remeter doações de lotes de terras ao MST. Após esse período, o distrito que compreendia a Fazenda Anonni se emancipou, tornando o assentamento, então, parte do novo município (Pontão) 
na forma como se estruturam, desde a maior mobilização, até a conversação com o governo e a forma de atribuir poderes para uma maior relação e debates dos seus temas. Simeone (2007) analisa os MS no século XX, classificando-os como novas movimentações sociais. Aqui, traremos também a análise de Castells (2013), o qual fala que as mídias digitais buscam outra forma de integração desses movimentos, um novo jeito de aparição e mobilização, sem precisarem, para tanto, das mídias tradicionais.

Seguindo nessa linha, vamos abarcar a comunicação e a visibilidade que os MS buscam em suas trajetórias. Utilizaremos, para isso, as reflexões de Downing (2004), que expressa a relevância da comunicação, porém ressalta a importância de que ela comece, principalmente, de dentro para fora. Ou seja, "a comunicação efetiva no interior dos movimentos sociais e praticada por eles é, portanto, uma necessidade vital para que a automobilização possa ocorrer e prosperar" (DOWNING, 2004, p.67).

Dessa forma, vamos abarcar a partir do referencial teórico, dando uma aparato nos capítulos sobre OP, mídia e movimentos sociais até chegarmos ao resultado obtido pela pesquisa de opinião pública. Após esse trajeto teremos a luz do referencial a conclusão obtida através das respostas do público alvo: os jovens.

\section{MOVIMENTOS SOCIAIS: HISTÓRICO E FORMAÇÃO}

À década de 1980, aqui no Brasil, estão ligados os novos MS, voltados para o lado urbano da sociedade, e vinculados, de certa forma, à Igreja Católica. Nessa época, o entusiasmo sobre esses movimentos davam destaques à abertura do governo e os distanciava de um estado autoritário. Gohn (2003, p.26) coloca que esses MS começaram a ganhar destaque e "eram movimentos que tinham ganho expressão naquele período, embora eles tenham igualmente ressurgido no Brasil ao final dos anos 70 ".

Ao passar do tempo, esses movimentos sociais sofreram mudanças devido ao cenário político da época, o crescimento de instituições públicas e novas formas de avaliação e participação pública. Antes pautados pela elite política, os MS estavam, nessa época, descrentes e desgastados pela falta de legitimidade de seus ideais. "No decorrer dos anos 80, os movimentos sociais no Brasil passaram, no plano da atuação concreta e no plano das análises que lhes são feitas, da fase de otimismo para a perplexidade e, depois, para a descrença" (GOHN, 2003, p. 29).

As mudanças na forma como os MS se organizaram começaram como 
uma forma de atrair pessoas engajadas em protestos nas ruas, divulgando os seus objetivos e atingindo satisfatoriamente satisfatória a mídia. Na segunda fase, os MS se organizaram internamente em associações, mais voltados em fortalecer a comunicação em seus canais internos para gerar engajamento. Por esse motivo, não tiveram aparições midiáticas. Como salienta Downing (2004, p. 67), "a comunicação efetiva no interior dos movimentos sociais e praticada por eles é, portanto, uma necessidade vital para que a automobilização possa ocorrer e prosperar".

Outra fase importante para se entender os MS, ainda de acordo com Downing (2004), é a fase de articulação, quando os movimentos passam a não enfrentar o governo e, sim, a achar uma forma de debater e colocar em pauta os assuntos de interesse público. Em um quarto momento, aceitam parcerias e buscam aliar-se com outras entidades para fortalecer os ideais e buscar reconhecimento da sua importância perante a sociedade atual. Nesse momento, os MS começam a profissionalizar a forma como se relacionam com a mídia de massa, buscando profissionais da comunicação para lidar com esse relacionamento. É o profissionalismo nas relações com a mídia que garante a esses grupos as conquistas mais notáveis nesse novo cenário: a colocação, na agenda pública, de discussões dos temas representados por eles e o seu prestígio junto à opinião pública.

Também é importante perceber que a evolução dos MS atravessa a evolução dos meios de comunicação. Quando novas mídias, como a radical, citada anteriormente, começam a serem valorizadas, os próprios movimentos dão início à criação de seus materiais de divulgação. A mídia, independente do tipo, confere um apoio muito importante para a criação da plataforma de ação utilizada pelos militantes. Nesse processo, a internet surge como aliada, oferecendo mais uma forma de exposição.

Diferentes formas de expressões e práticas culturais podem oferecer a possibilidade de novas formas de identidade, gerando novos significados aos acontecimentos. Os movimentos e grupos sociais organizados tentam também criar sua própria mídia, quer seja para divulgarem suas notícias e ideias, quer seja para registrarem suas estórias e tradições, criando suas próprias histórias (GOHN 2000, p. 24).

A mídia se torna um processo fundamental na existência dos MS, pois é do jeito que ela os reporta que construiremos, em nosso imaginário, opiniões sobre os movimentos. As estratégias da mídia também são de gran- 
de importância, pois os movimentos, ou os movimentos são manchetes, ou são ignorados - tudo isso dentro de noções políticas e ideológicas. É ao encontro dessa questão que a nossa pesquisa de opinião procurará entender como são retratados os MS, considerando se, na percepção dos jovens, a mídia influencia de alguma forma.

\begin{abstract}
A mídia tem retratado os movimentos segundo certos parâmetros político-ideológicos dados pela rede de relações a que está articulada. Os interesses políticos e econômicos formatam as considerações e as análises que configuram a apresentação das informações, denotando um processo onde a notícia é construída como mensagem para formar uma opinião pública sobre o acontecimento, junto ao público consumidor, não para informar este mesmo público. (GOHN, 2003, p. 23).
\end{abstract}

A história da mídia se confunde com a história dos movimentos sociais e, é através dela, que eles conseguem difundir seus ideais. Vários estudos apontam a importância da mídia e como os movimentos tendem a enfatizar a sua atuação "caracterizando-a como filtro ou espelho dos movimentos sociais" (GOHN, 2000, p. 39).

Quando, entre as décadas de 1990 e 2000, a internet começou a tomar grandes proporções, ativistas tomaram a iniciativa de desenvolver novas formas de adesão às suas causas. Os militantes criam links, desenvolvem campanhas e a divulgam nesse novo espaço sem restrições de editorias. Para Gohn (2000, p. 31), "campanhas e mobilizações ganham rapidez e desenvoltura num ativismo digital que democratiza as informações, cruza as idéias e plataformas de ações". Os movimentos buscam outras maneiras de ocupar os espaços públicos, uma vez que estamos vivendo um processo de mudança na forma de agir, saindo do ambiente digital para os movimentos ativos nas ruas, buscando alcançar a mudança social.

$O$ processo transformador chegou às redes sociais. A era da conectividade proporcionou para os movimentos um espaço público deliberado, com uma comunicação autônoma, características intrínsecas dos movimentos sociais. Essas novas formas, atreladas às três características dos movimentos sociais engajados na internet, veem ao encontro de uma nova forma de protesto: livre, imediata e compartilhada instantaneamente. A comunicação é a grande chave para as novas formas dos movimentos, é uma forma que permite que aos MS disseminarem e controlarem essas informações. 


\section{AJUSTANDO CONCEITOS: MOBILIZAÇÃO SOCIAL E MOVIMENTOS SOCIAIS}

Os termos mobilização social e movimentos sociais são recorrentemente utilizados para assuntos referentes em diversas áreas e, muitas vezes, tem seus significados confundidos devido à proximidade. Para os compreendermos com clareza, apresentaremos a distinção entre eles, com base nas teorias apresentadas por Gohn (2003), Mafra (2010) e Toro e Werneck (1996).

A mobilização social envolve muito mais do que um aglomerado de pessoas reivindicando algo em lugares públicos. Conforme Toro e Werneck (1996, p. 5), "mobilizar é convocar vontades para atuar na busca de um propósito comum, sob uma interpretação e um sentido também compartiIhados". A mobilização, então, ocorre quando grupos de pessoas buscam e agem de acordo com um objetivo comum decidido por todos.

Agrupar indivíduos é um processo da competência mobilizadora dos MS que parte de um princípio motivador das suas próprias causas e defesa dos ideais. Porém, esses grupos vinculados a determinado assunto, mobilizam-se diferentemente um do outro, pois cada um assume um papel diferenciado no processo. O vínculo entre eles também pode variar de intensidade, cada um se distinguido no que pode contribuir e agindo em prol da causa aderida. Ao perceber que esse vínculo criado é variável, Henriques (2010, p. 108) reforça que "podemos considerar que a força desses vínculos pode variar para cada integrante de um grupo mobilizador e também pode variar ao longo do tempo, conforme o curso da própria mobilização".

O ponto mais importante da mobilização é que ela também faz parte da comunicação. A arte de mobilizar não significa fazer publicidade, mas, sim, compartilhar informações, discursos sobre o mesmo ideal, sobre a pauta que norteia a ação. Ainda, é muito importante a valia de cada indivíduo, já que é através das atuações diárias que se pode ajudar e construir a mobilização social. Na visão de Toro e Werneck (1996, p. 5), “o que dá estabilidade a um processo de mobilização social é saber que o que eu faço e decido, em meu campo de atuação quotidiana, está sendo feito e decidido por outros, em seus próprios campos de atuação, com os mesmos propostos e sentidos".

Como já vimos, a função da mobilização é agrupar indivíduos sobre um mesmo ideal e compartilhar informações para angariar mais participantes. Os movimentos sociais partem desse princípio, porém atuam diretamente em demonstrações públicas sobre suas reivindicações. Mafra (2008, p. 
34) salienta que mobilizar vai além de agrupar indivíduos por uma causa e acrescenta que "a mobilização social não significa apenas reunião de indivíduos em torno de uma ação específica. Essa junção deve pressupor, acima de tudo, um acordo mais amplo e definição de objetivos". Os movimentos sociais surgiram através de um ideal marxista, como citado no capítulo anterior, e seu principal motivador são reivindicações por mudanças sociais.

\section{APLICAÇÃo E RESULTADO DA POP}

Para esclarecer como se forma a opinião pública dos jovens sobre os movimentos sociais, em especial o MST, realizamos uma pesquisa de opinião pública5, na tarde do dia 13 de maio de 2014, com 157 jovens da escola de ensino médio da cidade de Ronda Alta: Escola Estadual de Educação Básica Professor Alfredo Gavioli.

O questionário foi dividido em conhecimentos de gênero e de temas específicos, perpassando primeiramente em sexo, idade e nível de escolaridade. Após, passamos para as perguntas de como o público busca sua informação até chegarmos na parte de conhecimentos dos movimentos sociais e a atuação do MST. Apontaremos alguns dos resultados mais importantes para chegarmos a interpretação de como se forma a opinião pública dos jovens sobre o MST.

Os entrevistados têm, em sua maioria, de 14 a 16 anos. A Tabela 2 apresenta os números e a porcentagem da idade dos alunos entrevistados durante a pesquisa. É interessante observar que havia uma terceira opção. Porém, como não houve respostas, ela não foi tabulada.

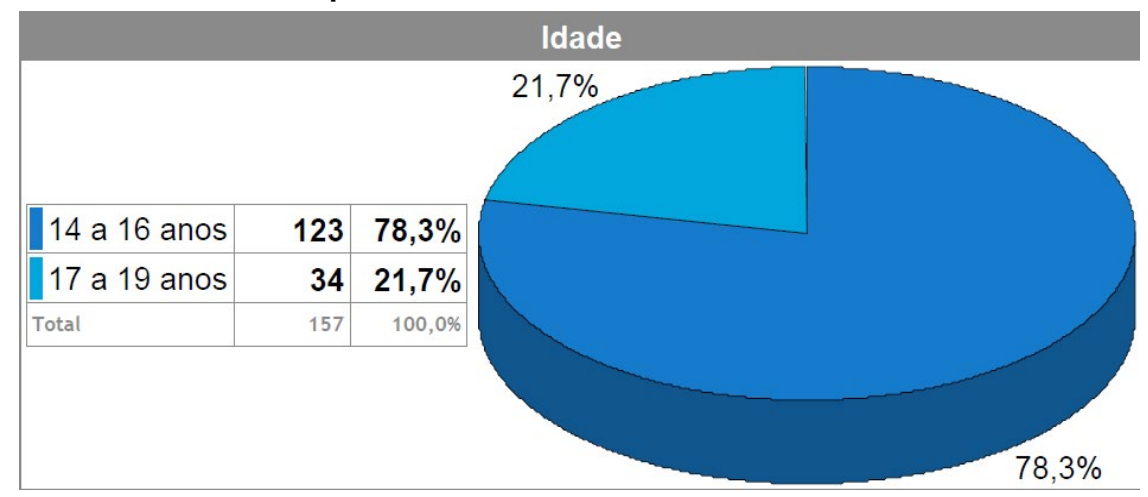

Tabela 1 - Idade dos jovens entrevistados.

5 A instituição possui 2258 alunos, a margem de erro estabelecida em $5 \%$ e o nível de confiança em $95 \%$. 
Ao investigarmos sobre o grau de escolaridade - dados da Tabela 2 -, vimos que $49 \%$ são alunos do $1^{\circ}$ ano do Ensino médio. Na sequência, está o $2^{\circ}$ ano, com $26,1 \%$, e, por último o $3^{\circ}$ ano, com menor percentual os alunos (24,8\%). Quando perguntados por qual meio se informam, conforme demonstra a Tabela 3, a maioria dos jovens entrevistados respondeu internet, obtendo uma porcentagem de $45,2 \%$. Com a margem de erro de $5 \%$, há um empate técnico entre a primeira opção e a segunda, a televisão com 43,1\%. A opção que menos obteve respostas foi 'amigo/parente', com apenas $2,4 \%$ das respostas. A tabela em questão apresenta a porcentagem e o número absoluto de quais os meios técnicos de comunicação que os jovens procuram para buscar a informação.

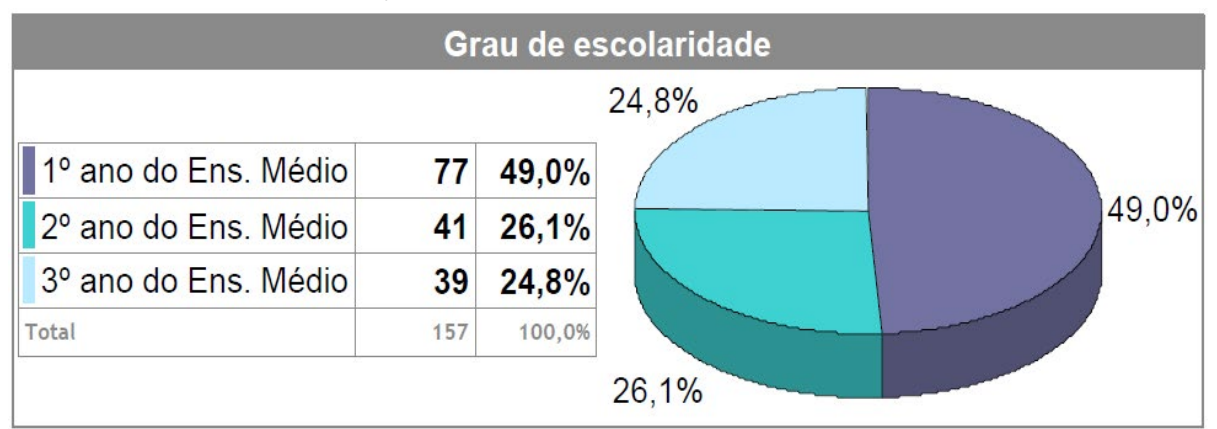

Tabela 2 - Escolaridade dos jovens entrevistados.

\begin{tabular}{|c|c|c|c|}
\hline \multicolumn{4}{|c|}{ Os jovens informam-se por: } \\
\hline Internet & 131 & $45,2 \%$ & $45,2 \%$ \\
\hline Televisão & 125 & $43,1 \%$ & $43,1 \%$ \\
\hline Rádio & 15 & $5,2 \%$ & $5,2 \%$ \\
\hline Jornal impresso & 12 & $4,1 \%$ & $4,1 \%$ \\
\hline Amigo/Parente & 7 & $2,4 \%$ & $2,4 \%$ \\
\hline Outro & 0 & $0,0 \%$ & $0,0 \%$ \\
\hline Total & 290 & $100,0 \%$ & Questão múltipla escolha \\
\hline
\end{tabular}

Tabela 3 - Onde os jovens se informam.

Quando questionados sobre os temas sociais de maior relevância, conforme a Tabela 4, tivemos como índices mais expressivos a 'educação', com $39,5 \%$, e a 'saúde', com 39,1\%. Dessa forma, tendo em vista a margem de erro adotada, podemos considerar um empate técnico entre os dois temas. Todas as outras opções ficaram entre $5 \%$ e $4 \%$, porcentagens baixas em relação aos dois temas mais reconhecidos pelos jovens. A opção correspondente ao MST ficou com um índice baixo, com apenas $4,4 \%$ dos jovens assinalaram esse tema como relevante. 


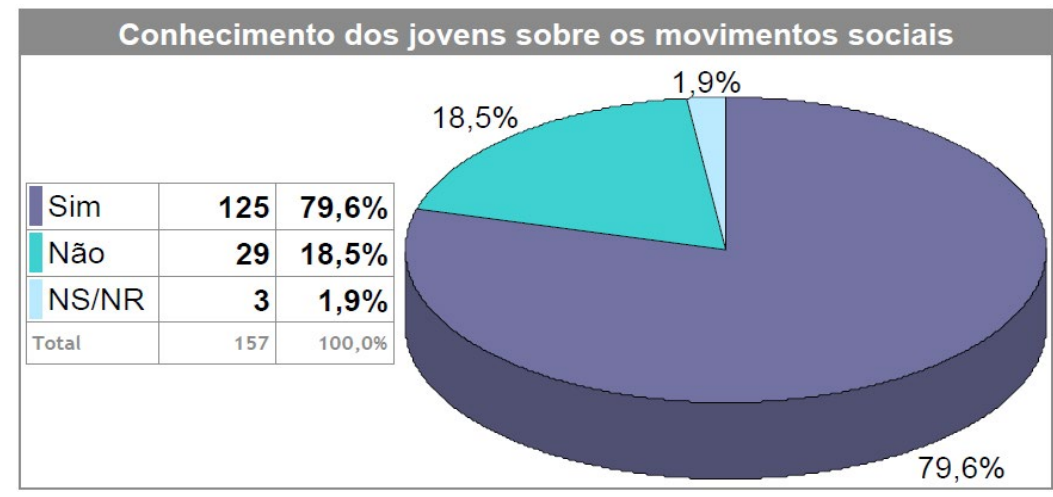

Tabela 4 - Conhecimento dos movimentos sociais pelos jovens.

Na Tabela 14, temos a porcentagem e os números reais de quantos alunos conhecem o MST. A grande parcela dos jovens conhece o movimento em questão, ficando com $86 \%$ de respostas positivas. Apenas $8,3 \%$ marcaram a opção 'não', que fica em um empate técnico com os jovens que não lembram sobre o MST, considerando a margem de erro.

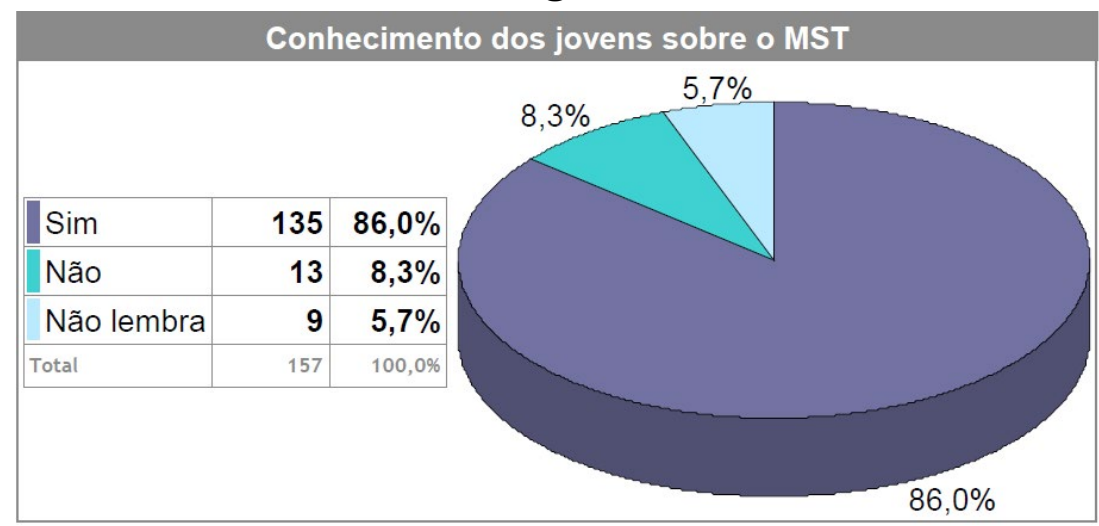

Tabela 5 - Conhecimento dos jovens sobre o MST.

O ponto principal da análise da questão da Tabela 6 é entender como os jovens acham que a mídia retrata os movimentos sociais, com ênfase no objeto empírico, o MST. Os entrevistados assinalaram a neutralidade como maior resultado, com 54,1\% das respostas. A opção 'negativo' chegou quase a 30\%. Entre 'positivo' e NS/NR houve um empate técnico, com baixo percentual de respostas em relação às outras duas opções.

\begin{tabular}{|c|c|c|c|}
\hline \multicolumn{4}{|c|}{ Na sua opinião, o que a mídia fala sobre o MST é frequentemente: } \\
\hline Neutro & 85 & $54,1 \%$ & $54,1 \%$ \\
\hline Negativo & 47 & $29,9 \%$ & $29,9 \%$ \\
\hline Positivo & 13 & $8,3 \%$ & $8,3 \%$ \\
\hline NS/NR & 12 & $7,6 \%$ & $7,6 \%$ \\
\hline Total & 157 & $100,0 \%$ & \\
\hline
\end{tabular}

Tabela 6 - Opinião sobre a forma com que a mídia retrata o MST. 
Após a apresentação de todas as tabelas, vamos, agora, passar para o próximo tópico do estudo. Entraremos em uma análise mais aprofundada dos resultados obtidos e delinearemos uma compreensão deles, tendo, como base, a contrapartida do referencial teórico trabalhado nos capítulos anteriores e a apresentação da conclusão do trabalho.

\section{CONCLUSÃO}

A importância de, hoje, estudarmos o contexto dos movimentos sociais, a estrutura da sociedade e, em linhas gerais, as formas de poder, é em linhas gerais o fato de possuirmos um maior entendimento do potencial de discutibilidade dos fatos que mobilizam o país. A concentração de um grande número da população reivindicando por melhorias nos faz repensar o processo evolutivo dos movimentos sociais e nos auxilia em perceber como esse engajamento é importante para a sobrevivência dos mais antigos movimentos sociais, como o MST, por exemplo.

Sabemos também que a opinião pública parte do principio de formulação de pensamentos e sentimentos de cada indivíduo, ou seja, de uma opinião privada. A partir disso, entendemos que, a partir de um processo de construção de informação das mídias, podemos formar nossas próprias maneiras de abarcar assuntos e entrar em discussões com mais veemência, possuindo o embasamento necessário.

Percorrendo todo o processo teórico, bem como a aplicação da pesquisa de opinião pública, percebemos que a formação da opinião dos jovens investigados acerca do tema proposto não está explicitamente ligada ao que a mídia diz, mas, de alguma forma, ligada ao que a mídia não reproduz. Esse entendimento veio da percepção de que a estratégia adotada pela mídia em não anunciar as ações do MST em rede nacional interfere no conhecimento dos jovens sobre o movimento. Porém, esse processo isolado não causa a não visibilidade do movimento, pois ela está atrelada também ao enfraquecimento do movimento a cerca de suas ações, visto que muitos jovens entrevistados não reconhecem o MST como movimento social, pois acreditam que esteja descaracterizado como tal.

Outro fator que contribuí para o não conhecimento dos jovens em relação ao que a mídia diz do MST vem do movimento estar cada vez mais organizado, com assessoria própria, monitorando suas ações e divulgando-as em seus meios de comunicação. Ao longo da história do movimento, vimos que grande parte de suas ações estavam ligadas à destruição e à desordem 
social e, após a reformulação, o movimento mudou, buscando formas mais estratégicas de ser representado midiaticamente. Vários fatores, como o silêncio da mídia, atrelado ao enfraquecimento da proposta de movimento social, interligados à nova postura estratégica, podem ser atribuídos como motivos para a pouca visibilidade do MST nos meios de comunicação de massa. Dessa forma, o sentido noticioso acaba circulando mais nos canais de disseminação de informação próprios do movimento.

Vimos, através do trabalho, que os movimentos sociais buscam um espaço para pautar a mídia, porém essa visibilidade ainda não está ativa nos meios de comunicações atuais. No entanto, o uso das novas formas de difundir seus ideais e plataformas de trabalho ajudaram a alavancar essa busca por atuar na agenda midiática, a partir de ações centralizadas na internet, espaço onde cada vez mais os jovens procuram a informação. Percebemos que a influência das 'novas mídias', muitas vezes, faz com que os meios de comunicação tradicionais a utilizem como fonte de informações, retratando os acontecimentos do ciberespaço em suas pautas.

Como visto inicialmente e confirmado ao longo da pesquisa, os meios de comunicação de massa (principalmente os telejornais) introduzem uma forma mais influente quando o quesito é formação de opinião. Percebemos isso ao recorrer ao nosso referencial teórico, onde a mídia tradicional caracterizou grandes processos de abertura e de acesso a informações.

$O$ estudo também nos mostrou que o governo influencia nesse processo de neutralidade midiática apontado pelos alunos nos questionários aplicados. Quando o MST começou a organizar-se, como um movimento politizado, os integrantes foram em busca de novas formas de para inserção de suas reivindicações nas pautas governamentais, como a reforma agrária e a necessidade de mais assentamentos legalizados pelo governo. Segundo Gohn (2013), a importância de estarmos ligados ao processo político-administrativo brasileiro se faz necessário para que possamos entender as dinâmicas dos movimentos sociais e de como os mesmos vão se reorganizando a partir das estruturas administrativas vigentes no país.

Através dos apontamentos que realizamos - entendendo o maior ou menos grau de influência da mídia e as estratégias de silêncio adotadas pela mesma, juntamente com a nova forma de o MST se organizar e da proposta de abertura do governo para à conversação -, com base nas respostas dos entrevistados, percebemos que a opinião dos jovens sobre o movimento ainda é superficial, uma vez relacionada a todo o aparato histórico de retratação 
midiática e de ações desse movimento. Visto que a maioria dos trabalhos apontados pelo estudo da arte, apontam que a mídia tradicional, ainda divulga de forma negativa as ações do MST, porém podemos contrapor essa informação visto que, esses trabalhos, datam de um longo período anterior a organização do MST no ciberespaço e a abertura de diálogo com o governo.

Ainda, nesse sentido, entendemos que há mais campos de estudos a serem explorados nessa temática. Uma possibilidade é a de indagar a formulação da opinião pública em diversas faixas etárias da população, visando com que entendamos o processo de influência midiática em cada geração. Essa seria uma forma de investigarmos, por exemplo, se o grau de instrução modifica as opiniões e se gera mais veracidade em assuntos de discutibilidade pública.

Por fim, concluímos que a mobilização, a visibilidade, as estratégias comunicacionais e o diálogo são processos importantes para que os MS se mantenham atualizados e sobrevivam em um mundo cada vez mais segmentado. É dessa forma que eles conquistam uma das partes mais importantes de seu processo reivindicador: aderir e conquistar espaço na opinião pública.

\section{REFERÊNCIAS}

AUGRAS, Monique. Opinião Pública: Teoria e pesquisa. 2. ed. Rio de Janeiro: Editora Vozes, 1974.

CASTELLS, Manuel. A sociedade em rede. A era da informação: economia,sociedade e cultura. 6. ed. São Paulo: Paz e Terra, 2000.

Janeiro: Zahar, 2013.

. Redes de indignação e esperança: movimentos sociais na era da internet. Rio de DOWNING, John D. H. Mídia Radical: rebeldia nas comunicações e movimentos sociais. 2. ed. São Paulo: Editora Senac São Paulo, 2004.

GIL, Antonio Carlos. Métodos e técnicas de pesquisa social. São Paulo: Atlas, 1987.

GOHN, Maria da Glória. Mídia, Terceiro Setor e MST: impactos sobre o futuro das cidades e do campo. Petrópolis: Vozes, 2000.

. Movimentos sociais no início do século XXI. Petrópolis, RJ: Vozes, 2003.

. Novas teorias dos movimentos sociais. São Paulo: Loyola, 2008.

. O protagonismo da sociedade civil: movimentos sociais, ONGs e redes de solidárias. 2. ed. São Paulo: Cortez, 2008.

. Os Sem Terras, ONGs e Cidadania. São Paulo: Cortez, 2003.

. Sociologia dos movimentos sociais. São Paulo: Cortez, 2013. 
. Teoria dos Movimentos Sociais- paradigmas clássicos e contemporâneos. São

Paulo: Loyola, 1997.

HABERMAS, Jürgen. Mudança estrutural da Esfera Pública: investigações quanto a uma categoria da sociedade burguesa. 2. ed. Rio de Janeiro- RJ: Tempo Brasileiro, 2003.

MAFRA, Rennan. Entre o espetáculo, a festa e a argumentação - a mídia, comunicação estratégica e mobilização. Belo Horizonte: Autêntica, 2008.

MAFRA, Renan. Mobilização Social e comunicação: por uma perspectiva relacional. Mediação, Belo Horizonte, Vol. 11, n. 10, jan/jun. 2010. Disponível em http://www.fumec.br/ revistas/index.php/mediacao/article/view/310. Acesso em 23 de abril de 2014 às 22h16min.

SECRETARIA NACIONAL DO MST. Cartilha MST: Lutas e conquistas. São Paulo, 2010.

SIMEONE, M. Ativismo, movimentos sociais e relações públicas. In: KUNSCH, Margarida M. Krohling; KUNSH, Waldemar Luiz. Relações Públicas Comunitárias: a comunicação em uma perspectiva dialógica transformadora. São Paulo: Summus, 2007, p.92-105.

SIMEONE, Márcio H. Comunicação e mobilização social na prática da polícia comunitária. Belo Horizonte: Autêntica, 2010.

PERUZZO, Cicilia Krohling. Comunicação nos movimentos populares: a participação na construção da cidadania. Petropolis, RJ: Vozes, 1998

. Relações Públicas no modo de produção capitalista. 2. ed. São Paulo: Summus, 1986.

RECUERO, Raquel. Redes sociais na Internet. Porto Alegre: Sulina, 2009

TORO, José B.; WERNECK, Nísia M. D. Mobilização Social: um modo de construir a democracia e a participação. 2. ed. Belo Horizonte: Autêntica, 1996.

VESTENA, C. Luciana. O papel da mídia na formação da opinião pública: a contribuição de Bourdieu. Paraná, 2008. <http://revistas.unicentro.br/index.php/guaiaraca/article/ viewFile/1144/1089>. Acesso em: 26 set. 2013. 


\section{Anelise Lorenzon Machado}

Bacharel em Relações Públicas-Ênfase em Multimídia pela Univerisade Federal de Santa Maria, campus Frederico Westphalen. Atualmente é Assessora de Comunicação na empresa Digifred. E-mail:machado_anelise@hotmail.com

\section{Patrícia Milano Pérsigo}

Professora Assistente do Departamento de Ciências da Comunicação da UFSM, campus Frederico Westphalen. Doutoranda e Mestre em Comunicação nesta mesma instituição de ensino. Especialista em Marketing e Recursos Humanos pela Faculdade Metodista de Santa Maria e Bacharel em Comunicação Social, habilitação em Relações Públicas pela UFSM. Atualmente pesquisa a atuação da mídia e o jornalismo público. Integrante do grupo de pesquisa Comunicação Institucional e Organizacional, vinculado ao CNPq. E-mail: patricia.persigo@ufsm.br 